\title{
Physicochemical and thermodynamic properties of solutions of clary sage (Salvia sclarea L.) essential oil in ethanol-water system
}

\author{
Stanislava Tasheva ${ }^{1, *}$, Vanya Gandova $^{1}$, Krasimira Dobreva $^{2}$, Vanya Prodanova- \\ Stefanova ${ }^{2}$, Krasimira Marinova ${ }^{3}$, Ivayla Dincheva ${ }^{4}$, and Albena Stoyanova ${ }^{1}$ \\ ${ }^{1}$ University of Food Technologies, Plovdiv, 4002, Bulgaria \\ ${ }^{2}$ Trakia University, Dept. Food Technology, Yambol, 8600, Bulgaria \\ ${ }^{3}$ University Prof. Dr. Assen Zlatarov-Burgas, Central scientific research laboratory, 8010, Bulgaria \\ ${ }^{4}$ Agrobioinstitute, Sofia, 1164, Bulgaria
}

\begin{abstract}
Clary sage (Salvia sclarea L.) essential oil-ethanol-water system was investigated. The surface tension, density and refractive index of clary sage essential oil + ethanol $(70 \%, 75 \%, 80 \%, 85 \%, 90 \%$, and 95\%) solutions were measured. The chemical composition of solutions (ratio 1:5, 1:6, and 1:7) was determined using GC/MS analysis. According the experimental results ternary phase diagrams were constructed. Comparative revue between experimental and calculated surface tension data was done. After analyses good correlation between two surface tension values was observed
\end{abstract}

\section{Introduction}

Essential oil obtained from plants and used in pharmaceutical, perfumery, cosmetics, and alimentary industries as flavor and taste correctives for different products. They consist of a complex mixture of volatile, lipophilic substances that are mainly hydrocarbons and their oxygenated derivatives of aliphatics, terpenes, and phenyl propanoids compounds.

Physicochemical properties (density, viscosity, etc.) of essential oils and their volatile compounds in ethanol-water systems were studied by different authors [1-5]. The obtained experimental results presented equilibrium in the systems in the studied temperature range [1]. The temperature dependence of the density and refractive indexes was investigated and described as linear form [2,3]. The measurements of surface tension and interfacial tension against water for mint, lemon and oregano oils were provided as a function of time and temperature [4]. Pure alcohols such as linalool, geraniol, nerol, etc. or alcohols mixed with ethanol-water system were used as solvents in industrial applications of different perfumery and cosmetic products. Some physical properties such as density, viscosity, refractive index and surface tension of ethanol and water mixtures were measured at a temperature of $25^{\circ} \mathrm{C}$ [5].

\footnotetext{
*Corresponding author: st tasheva@abv.bg
} 
Influence of some factors - temperature, pressure, concentration of solvent into solutions of different terpenic compounds such as monoterpene hydrocarbons $(\alpha-$ and $\beta$ pinene, $\delta 3$-carene, limonene, etc.), and oxygenated monoterpenes (camphor, fenchone, linalool, etc.) are investigated from different authors [6-14].

Some kinetics and thermodynamic properties of oilseed were investigated [15-17]. The coefficient of thermodynamic conductivity was investigated and determined of [15]. Heat capacity was determined with change between ethanol-water [16]. Some empirical correlations have reasonable success and discussion of molecular theories related to the liquid phase and some empirical correlations of thermal conductivity, presented in [17].

Clary sage oil is obtained by steam distillation of flowes of cultivated in Bulgaria Salvia sclarea L. belongs to Lamiaceae family. The essential oil is a pale yellow to yellow liquid with a fresh herbaceous odor. The essential oil content the oxygenated monoterpenes linalyl acetate, linalool and other terpene alcohols, as well as their acetates. Clary sage essential oil demonstrated antimicrobial, antiinflamatory, antioxidant, antiviral, and insecticidal activities and used extensively in perfumery and different cosmetic products. [18].

The aim of this study is to investigate some physicochemical and thermodynamic properties in the ternary clary sage oil-ethanol-water system. The system is used in perfumery and food products that use alcoholic solutions.

\section{Materials and methods}

\subsection{Materials}

All solutions are prepared with distilled water. Clary sage oil was provided by Kateko Ltd, Bulgaria and 95\% ethanol by FILLAB, Bulgaria.

\subsection{Methods}

\subsubsection{Solution}

The solutions on 18 samples of clary sage oil: ethanol mixture were prepared in six series.

The prime composition of all samples are presented in Figure 1. From the $95 \%$ starting ethanol, $70 \%, 75 \%, 80 \%, 85 \%, 90 \%$ ethanol are diluted with distilled water.

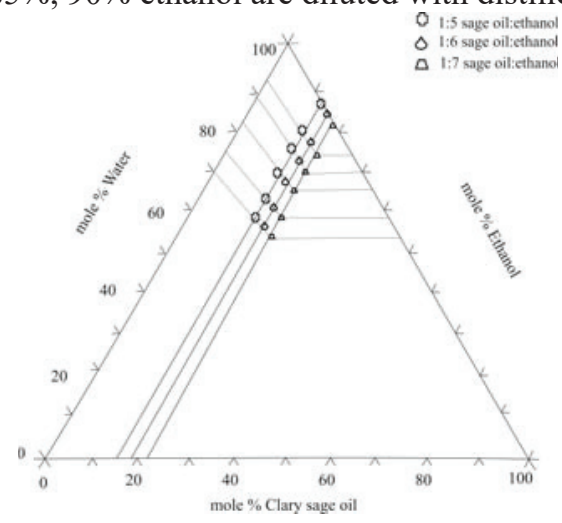

Fig. 1. Primary composition of 18 samples of the clary sage oil-ethanol-water system. 


\subsubsection{Physco-chemical analysis of the solutions}

The preparation of solutions and the experimental procedure as determined surface tension, density and refractive index were determined experimentally and described from authors [14]. The studied physicochemical properties of the solutions (density, refraction and surface tension) are performed at the temperature of $25{ }^{\circ} \mathrm{C}$ and the pressure of $1.10^{5} \mathrm{~Pa}$ (atmosphere pressure).

\subsubsection{Chemical analysis of the solutions}

The chemical analysis obtained of GC analysis was provided for six samples at all ethanol concentrations in ratio 1:5, which is the highest content of essential oil. This series contained the following ratio of clary sage oil:ethanol $=1: 5$. The samples contained the largest amount of clary sage oil and for this reason they were preferred as quantity of essential oil has an influence in the perfumery.

The GC analysis was performed using a GC Agilent 7890A, an HP-5 ms column (30 m x $250 \mu \mathrm{m} \times 0.25 \mu \mathrm{m}$ ), temperature: $35{ }^{\circ} \mathrm{C} / 3 \mathrm{~min}, 5{ }^{\circ} \mathrm{C} / \mathrm{min}$ to $250{ }^{\circ} \mathrm{C}$ for $3 \mathrm{~min}$, total: 49 $\mathrm{min}$; helium as a carrier gas at $1 \mathrm{~mL} / \mathrm{min}$ constant speed, and 30:1 split ratio.

The GC/MS analysis was carried out on an Agilent 5975C mass spectrometer, using helium as a carrier gas, and the same column and temperature as in the GC analysis.

The identification of chemical compounds was performed by comparison to their relative retention indexes and library data. The identified constituents were arranged in order of retention time and quantity in percentage.

\subsubsection{Thermodynamic parameters}

The thermodynamic parameters (free energy of Gibb's, entropy, enthalpy and activation energy) are criterion for thermodynamic stability for system. The values determine that the process is irreversible and give the information for the reaction mechanism.

$$
\begin{gathered}
\Delta G=-\ln K \cdot R \cdot T, J / \mathrm{mol} \\
\Delta G=\Delta H-T \cdot \Delta S, J / \mathrm{mol} \\
\Delta H=E_{a}-R T, J / \mathrm{mol} \\
E_{a}=2,31 \cdot \operatorname{tg} \alpha \cdot R T, J / \mathrm{mol}
\end{gathered}
$$

where: $R$ is the universal gas constant, $T$ is the absolute temperature, $K$ is equilibrium constant, $\Delta S$ is the entropy, $\Delta \mathrm{H}$ is the enthalpy, $\Delta G$ is the free energy or Gibb `s energy, $E_{a}$ is the activation energy, $\alpha$ - degree of slope determined from $\operatorname{lnK}$ vs $1 / \mathrm{T}[16,19-26]$.

\subsubsection{Statistical analysis}

The measurements were performed in triplicate. The results were presented as a mean value of the individual measurements. 


\section{Results and discussion}

The essential oil was light yellow with a specific odor and had the following properties: density $0.8623 \pm 0.00 \mathrm{~kg} . \mathrm{cm}^{-3}$ and a refractive index $\left(\mathrm{n}_{D}^{20}\right) 1.4635 \pm 0.00$. The results are in accordance with the data from other authors [18].

\subsection{Physicochemical properties}

The studied physicochemical properties of the solutions (density, refraction and surface tension) are presented in Table 1. The studies were performed at the temperature of $25{ }^{\circ} \mathrm{C}$ and the pressure of $1.10^{5} \mathrm{~Pa}$ (atmosphere pressure).

According to data from Table 1 with an increase of ethanol in solutions, the density and refractive index decrease. The refractive index and density show a highest values in first solutions at $70 \%$ ethanol. This is connected with the properties of pure ethanol. The density and refractive index are, respectively $\left(\rho=0.789 \mathrm{~kg} \cdot \mathrm{m}^{-3}\right.$ and $\left.n=1.3617\right)$ [20]. These highest values are connected with higher stability of system.

Table 1. Physicochemical properties in clary sage oil-ethanol-water system.

\begin{tabular}{|c|c|c|c|c|c|}
\hline № & $\begin{array}{c}\text { ethanol, } \\
\%\end{array}$ & $\begin{array}{c}\text { ratio clary } \\
\text { sage oil:ethanol }\end{array}$ & $\begin{array}{c}\text { Density, } \\
\rho, 10^{-3} \mathrm{~kg} \cdot \mathrm{m}^{-3}\end{array}$ & $\begin{array}{c}\text { Refractive } \\
\text { index, } \mathrm{n}_{D}^{20}\end{array}$ & $\begin{array}{c}\text { Surface } \\
\text { tension, } \\
\gamma, \mathrm{mN.m}^{-1}\end{array}$ \\
\hline 1 & 70 & $1: 5$ & 0.862 & 1.4450 & 17.319 \\
\hline 2 & 70 & $1: 6$ & 0.859 & 1.4379 & 13.648 \\
\hline 3 & 70 & $1: 7$ & 0.858 & 1.3741 & 13.624 \\
\hline 4 & 75 & $1: 5$ & 0.852 & 1.3831 & 21.006 \\
\hline 5 & 75 & $1: 6$ & 0.851 & 1.3807 & 18.558 \\
\hline 6 & 75 & $1: 7$ & 0.847 & 1.3777 & 17.337 \\
\hline 7 & 80 & $1: 5$ & 0.840 & 1.3844 & 18.571 \\
\hline 8 & 80 & $1: 6$ & 0.839 & 1.3812 & 17.347 \\
\hline 9 & 80 & $1: 7$ & 0.836 & 1.3797 & 17.106 \\
\hline 10 & 85 & $1: 5$ & 0.830 & 1.3935 & 17.358 \\
\hline 11 & 85 & $1: 6$ & 0.828 & 1.3964 & 17.116 \\
\hline 12 & 85 & $1: 7$ & 0.827 & 1.3910 & 16.137 \\
\hline 13 & 90 & $1: 5$ & 0.819 & 1.3975 & 19.822 \\
\hline 14 & 90 & $1: 6$ & 0.818 & 1.3817 & 17.373 \\
\hline 15 & 90 & $1: 7$ & 0.821 & 1.3804 & 14.919 \\
\hline 16 & 95 & $1: 5$ & 0.805 & 1.3845 & 18.614 \\
\hline 17 & 95 & $1: 6$ & 0.802 & 1.3831 & 17.393 \\
\hline 18 & 95 & $1: 7$ & 0.801 & 1.3810 & 16.169 \\
\hline
\end{tabular}

The surface tensions of all samples were determined and presented in Table 1. The results have opposite values. In first solutions low surface tension was observed. Then in $75 \%$ ethanol solution increasing of tension was observed and the values of the following solution decrease. According [21] the presence of water greatly influences the surface tension of the samples and previous results are connected with current information. According to Table 1 some of the highest surface tension is approximately $21.006 \mathrm{mN} . \mathrm{m}^{-1}$ observed in solutions with $75 \%$ ethanol and high water content.

Linear regression was applied to presents the dependence between experimental and calculated values of surface tension. It was found that the predicted and observed values were in good agreement (Fig. 2). 


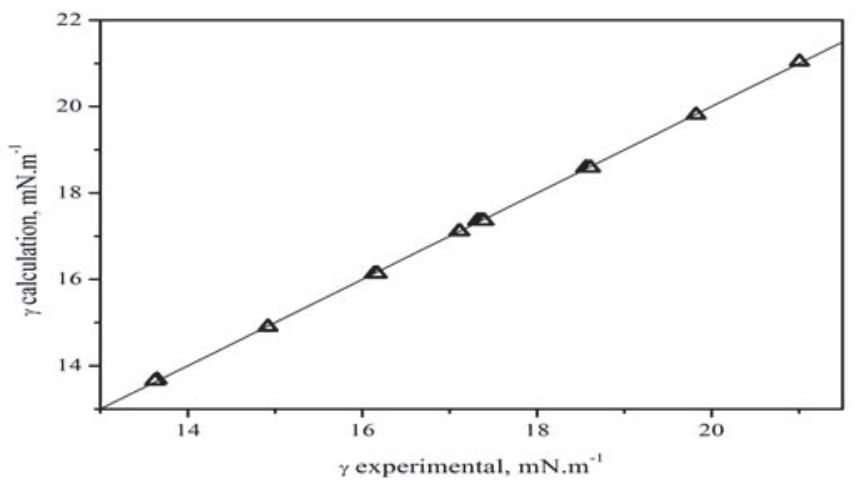

Fig. 2. Comparative review between experimental and calculated surface tension values.

\subsection{Chemical composition}

Chemical composition after GC analysis of essential clary sage oil in six solutions with ratio 1:5 oil:ethanol is presented in Table 2 .

Table 2. Chemical composition of the 6 ethanol-water solutions with clary sage essential oil

\begin{tabular}{|c|c|c|c|c|c|c|c|c|}
\hline Peak & Name & $\mathbf{R I}$ & $\mathbf{7 0 \%}$ & $\mathbf{7 5 \%}$ & $\mathbf{8 0 \%}$ & $\mathbf{8 5 \%}$ & $\mathbf{9 0 \%}$ & $\mathbf{9 5 \%}$ \\
\hline 1 & $\begin{array}{c}\text { (3E)-3-Hexen-1- } \\
\text { ol }\end{array}$ & 838 & 0.26 & 0.26 & 0.23 & 0.18 & 0.16 & 0.10 \\
\hline 2 & $\begin{array}{c}\text { (2E)-2-Hexen-1- } \\
\text { ol }\end{array}$ & 852 & 0.38 & 0.35 & 0.31 & 0.24 & 0.18 & 0.13 \\
\hline 3 & n-Hexanol & 855 & 0.45 & 0.41 & 0.37 & 0.29 & 0.23 & 0.16 \\
\hline 4 & n-Octan-1-en-3-ol & 978 & 0.19 & 0.22 & 0.20 & 0.18 & 0.24 & 0.14 \\
\hline 5 & n-Octanone-3 & 983 & 0.31 & 0.19 & 0.22 & 0.26 & 0.16 & 0.55 \\
\hline 6 & Limonene & 1023 & 0.16 & 0.08 & 0.10 & 0.11 & 0.37 & 0.26 \\
\hline 7 & $\beta$-(Z)-Ocimene & 1037 & 0.10 & 0.07 & 0.08 & 0.10 & 0.17 & 0.23 \\
\hline 8 & $\beta$-(E)-Ocimene & 1050 & 0.18 & 0.10 & 0.12 & 0.17 & 0.14 & 0.41 \\
\hline 9 & $\beta$-Linalool & 1095 & 40.07 & 41.76 & 38.82 & 36.53 & 34.69 & 30.85 \\
\hline 10 & Terpinen-4-ol & 1173 & 0.10 & 0.15 & 0.25 & 0.37 & 0.28 & 0.13 \\
\hline 11 & $\alpha$-Terpineol & 1187 & 9.40 & 9.58 & 8.46 & 7.60 & 6.45 & 5.37 \\
\hline 12 & Nerol & 1227 & 1.97 & 2.05 & 2.36 & 1.79 & 1.50 & 1.23 \\
\hline 13 & Geraniol & 1249 & 0.32 & 0.15 & 0.21 & 0.19 & 0.27 & 0.35 \\
\hline 14 & Nerol & 1254 & 35.93 & 34.10 & 36.75 & 40.06 & 42.93 & 46.81 \\
\hline 15 & $\begin{array}{c}\text { Linalool } \\
\text { propanoate }\end{array}$ & 1334 & 0.46 & 0.26 & 0.20 & 0.15 & 0.31 & 0.17 \\
\hline 16 & Neryl acetate & 1359 & 0.64 & 0.60 & 0.70 & 0.85 & 0.98 & 1.13 \\
\hline 17 & Geranyl acetate & 1378 & 1.30 & 1.10 & 1.39 & 1.68 & 2.04 & 2.41 \\
\hline 18 & $\beta$-Caryophyllene & 1419 & 0.45 & 0.14 & 0.18 & 0.30 & 0.64 & 1.12 \\
\hline 19 & Germacrene D & 1483 & 0.80 & 0.13 & 0.38 & 0.54 & 1.02 & 1.70 \\
\hline 20 & Cubebol & 1514 & 0.20 & 0.10 & 0.30 & 0.13 & 0.14 & 0.41 \\
\hline 21 & Spathulenol & 1577 & 0.29 & 0.25 & 0.23 & 0.21 & 0.19 & 0.14 \\
\hline
\end{tabular}




\begin{tabular}{|c|c|c|c|c|c|c|c|c|}
\hline 22 & $\begin{array}{c}\text { Caryophyllene } \\
\text { oxide }\end{array}$ & 1583 & 0.23 & 0.20 & 0.28 & 0.17 & 0.32 & 0.33 \\
\hline 23 & 7 -epi- $\alpha$-Eudesmol & 1661 & 0.26 & 0.40 & 0.60 & 0.67 & 0.61 & 0.63 \\
\hline 24 & $\begin{array}{c}\text { Eudesm-11-en- } \\
4 \alpha, 6 \alpha \text {-diol }\end{array}$ & 1809 & 0.52 & 0.42 & 0.12 & 0.23 & 0.40 & 0.13 \\
\hline 25 & $\begin{array}{c}\text { (Z,Z)-Farnesyl } \\
\text { acetone }\end{array}$ & 1863 & 0.26 & 0.28 & 0.20 & 0.15 & 0.22 & 0.18 \\
\hline 26 & Manool & 2054 & 0.13 & 0.15 & 0.27 & 0.22 & 0.18 & 0.21 \\
\hline 27 & Sclareol & 2222 & 3.26 & 4.92 & 4.76 & 5.04 & 3.86 & 3.22 \\
\hline & Total, $\%$ & 98.62 & 98.46 & 98.09 & 98.41 & 98.68 & 98.50 & 98.62 \\
\hline
\end{tabular}

Four components are influenced by the stability of system: $\beta$-linalool, nerol, $\alpha$ terpineol, sclareol. In solution with $70 \%$ ethanol the main constituents are presented with: $\beta$-linalool (40.07\%), nerol (35.93\%), $\alpha$-terpineol (9.40\%), sclareol (3.26\%).

In solution with $75 \%$ ethanol the main constituents are presented with: $\beta$-linalool (41.76\%), nerol (34.10\%), $\alpha$-terpineol (9.58\%), sclareol (4.92\%).

In solution with $80 \%$ ethanol the main constituents are presented with: $\beta$-linalool (38.82\%), nerol (36.75\%), $\alpha$-terpineol (8.46\%), sclareol (4.76\%).

In solution with $85 \%$ ethanol the main constituents are presented with: $\beta$-linalool (36.53\%), nerol (40.06\%), $\alpha$-terpineol (7.60\%), sclareol (5.04\%).

In solution with $90 \%$ ethanol the main constituents are presented with: $\beta$-linalool (34.69\%), nerol (42.93\%), $\alpha$-terpineol (6.45\%), sclareol (3.86\%).

In solution with $95 \%$ ethanol the main constituents are presented with: $\beta$-linalool (30.85\%), nerol (46.81\%), $\alpha$-terpineol (5.37\%), sclareol (3.22\%).

The oxygenated monoterpenes and oxygenated diterpenes are the dominant groups of chemical constituents in the solutions (Fig. 3). The oxygenated monoterpenes decreases content with the increasing of ethanol concentration. This is connected with the oil solubility in ethanol. The content oxygenated diterpenes first increases and then decreases.

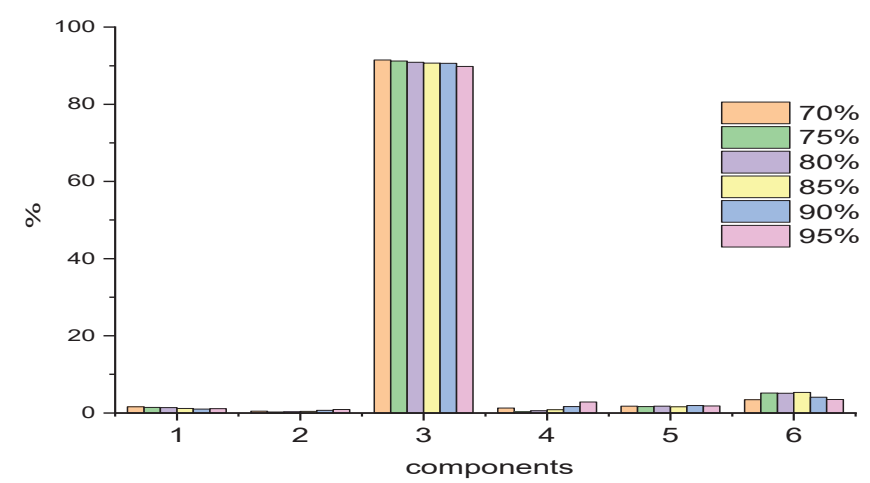

Fig. 3. Dependence between the groups of aroma substances in the clary sage oil in all solutions and ethanol \% of solutions. Components: 1- oxygenated hydrocarbons (3.81-4.40); 2- monoterpene hydrocarbons (1.33-3.41); 3 - oxygenated monoterpenes (89.10-93.58); 4 - sesquiterpene hydrocarbons $(0.04-0.16) ; 5$ - oxygenated sesquiterpene $(0.47-2.19) ; 6$ - oxygenated diterpenes $(0.27$ $0.74)$.

The main components of all solutions are $\beta$-linalool and nerol (oxygenated monoterpenes). With them was constructed the equilibrium phase diagram presented on 
Fig. 4. Symbols denote the point of equilibrium between each tree component ( $\beta$-linaloolethanol-water and nerol-ethanol-water).

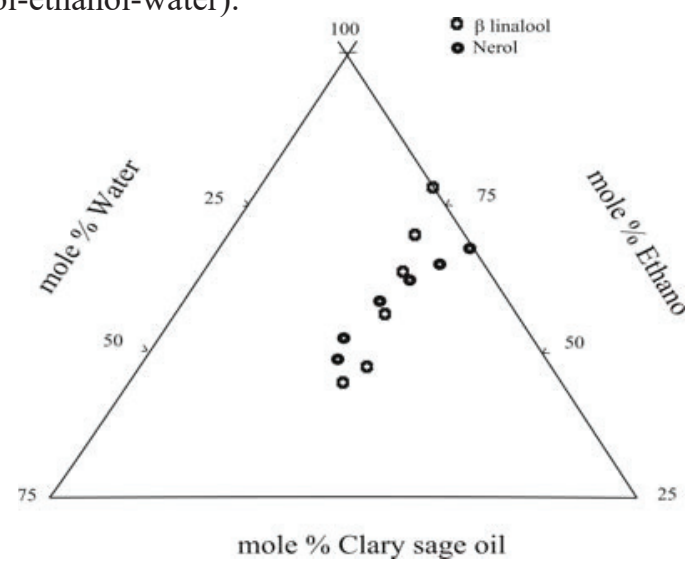

Fig. 4. Equilibrium phase diagram between $\beta$-linalool-ethanol-water and nerol-ethanol-water for the solutions with $70 \%, 75 \%, 80 \%, 85 \%, 90 \%$, and $95 \%$ ethanol

\subsection{Thermodynamic parameters}

In table 3 are presents values of the thermodynamic parameters (Gibb's free energy, entropy and enthalpy) of essential oil-ethanol-water system.

Table 3. Thermodynamic parameters of the essential oil-ethanol-water system

\begin{tabular}{|c|c|c|c|c|c|c|}
\hline № & $\begin{array}{c}\text { Ethanol, } \\
\%\end{array}$ & $\begin{array}{c}\text { ratio clary } \\
\text { sage } \\
\text { oil:ethanol }\end{array}$ & $\operatorname{lnK}$ & $\begin{array}{c}\Delta \mathrm{G}, \\
\mathrm{J} . \mathrm{mol}^{-1}\end{array}$ & $\begin{array}{c}\Delta \mathrm{H}, \\
\mathrm{J} \cdot \mathrm{mol}^{-1}\end{array}$ & $\begin{array}{c}\Delta \mathrm{S}, \\
\mathrm{J}^{-1} \mathrm{~mol}^{-1} \cdot \mathrm{K}^{-1}\end{array}$ \\
\hline 1 & 70 & $1: 5$ & 2.85 & -9559.35 & -2490.24 & 23.71 \\
\hline 2 & 70 & $1: 6$ & 2.61 & -8968.87 & -2490.24 & 21.73 \\
\hline 3 & 70 & $1: 7$ & 2.61 & -8964.51 & -2490.24 & 21.71 \\
\hline 4 & 75 & $1: 5$ & 3.04 & -10037.77 & -2490.24 & 25.31 \\
\hline 5 & 75 & $1: 6$ & 2.92 & -9730.63 & -2490.24 & 24.28 \\
\hline 6 & 75 & $1: 7$ & 2.85 & -9561.93 & -249024 & 23.72 \\
\hline 7 & 80 & $1: 5$ & 2.92 & -9732.36 & -2490.24 & 24.29 \\
\hline 8 & 80 & $1: 6$ & 2.85 & -9563.35 & -2490.24 & 23.72 \\
\hline 9 & 80 & $1: 7$ & 2.84 & -9528.68 & -2490.24 & 23.61 \\
\hline 10 & 85 & $1: 5$ & 2.85 & -9564.93 & -2490.24 & 23,73 \\
\hline 11 & 85 & $1: 6$ & 2.84 & -9530.12 & -2490.24 & 23.61 \\
\hline 12 & 85 & $1: 7$ & 2.78 & -9384.12 & -2490.24 & 23.12 \\
\hline 13 & 90 & $1: 5$ & 2.99 & -9893.96 & -2490.24 & 24.83 \\
\hline 14 & 90 & $1: 6$ & 2.85 & -9567.07 & -2490.24 & 23.74 \\
\hline 15 & 90 & $1: 7$ & 2.70 & -9189.59 & -2490.24 & 22.47 \\
\hline 16 & 95 & $1: 5$ & 2.92 & -9738.10 & -2490.24 & 24.31 \\
\hline 17 & 95 & $1: 6$ & 2.86 & -9569.92 & -2490.24 & 23.75 \\
\hline 18 & 95 & $1: 7$ & 2.78 & -9389.03 & -2490.24 & 23.14 \\
\hline
\end{tabular}

In Table 3 are presence thermodynamic parameters calculated on the basis experimental results obtained after dissolution of clary sage essential oil in ethanol-water solutions are shown. The results show that the process is spontaneous and irreversible. The negative Gibbs energy is connected with process occurrence and stability of system. The entropy is connected with mechanism of the reaction. In this case the positive values prove process 
irreversibility. With increasing of ethanol content in solution entropy values decrease which can be explained by the activating complex theory and the degrees of freedom. Negative enthalpy values mean that there will be better solubility of the essential oil in the alcohol solution if heat is introduced into the process. The activation energy was calculated and equal $\mathrm{Ea}=7.67 \mathrm{~kJ}^{\mathrm{mol}}{ }^{-1}$.

On the bases of calculated thermodynamic parameters specific heat capacity and coefficient of temperature expansion of the solutions were calculated. The obtained values are $\mathrm{Cp}=8.35 \mathrm{~kJ} \cdot \mathrm{mol}^{-1} \cdot \mathrm{K}^{-1}$ and $\beta=3.35 \cdot 10^{-3} \mathrm{~K}^{-1}$.

Distribution of main groups of aroma substances in the essential oil in all solutions is shown in Fig. 4. The high influence have the oxygenated monoterpenes $(90.77 \%)$ and the oxygenated diterpenes $(4.44 \%)$ followed by oxygenated hydrocarbons, monoterpene hydrocarbons, sesquiterpene hydrocarbons and oxygenated sesquiterpene.

\section{Conclusions}

The clary sage (Salvia sclarea L.) essential oil in solutions with different ethanol \% was investigated. Chemical composition of clary sage oil in solutions was obtained by using GC/MS analysis. Ternary equilibria between $\beta$-linalool-ethanol-water and nerol-ethanolwater was investigated and graphical presentation was done by phase diagram constuction. Thermodynamic parameters Gibbs free energy, enthalpy and entropy of solutions were calculated. Obtained results show that the dissolution process is irreversible and spontaneous. The activation energy of the process was calculated and have value of Ea $=$ $7.67 \mathrm{~kJ} . \mathrm{mol}^{-1}$. Thermodynamic parameters heat capacity and coefficient of temperature expansion of the solutions were calculated too. Obtained values were $\mathrm{Cp}=8.35 \mathrm{~kJ}^{\mathrm{m}} \mathrm{mol}^{-1} . \mathrm{K}^{-}$ ${ }^{1}$ and $\beta=3.35 \cdot 10^{-3} \mathrm{~K}^{-1}$.

\section{References}

1. R. Clará, A. Gómez Marigliano, V. del Campos, H. Sólimo, Fluid Ph. Equil. 293, 151$156(2010)$

2. S. Markarian and A. Terzyan, J. Chem. Eng. Data 52, 5 1704-1709 (2007)

3. V. Benkovskii, T. Bogoslovskaya, M. Nauruzov, Chem. and Tech. of Fuels and Oils 2, 23-26 (1966)

4. C. Arneodo, A. Baszkin, J-P Benoit, R. Fellous, C. Thies, Coll. and Surf. 34, 159-169 (1988/89)

5. R. Belda, J. Herraez, O. Diez, Phys. and Chem. of Liq. 43, $191-101$ (2005)

6. A. Marchiaro Arce, A. Soto, J. Sol. Chem. 33, 561-569 (2004)

7. S. Garcia-Abarrio, M. Torcal, M. Haya, J. Urieta, A. Mainar, J. Chem. Thermodynamics 43, 527-532 (2011a)

8. S. Garcia-Abarrio, L. Viloria, L. Haya, J. Urieta, A. Mainar, Fluid Ph. Equil. 308, 7889 (2011b)

9. M. Gramajo de Doz, A. Cases, H. Solimo, J. Chem. Therm. 40, 1575-1579 (2008)

10. K. Li, K.Tamura, Fluid Phase Equilibria 263, 223-20 (2008)

11. V. Štejfa, M. Fulem, K. Ruzicka, C. Cervinka, J. Chem. Therm. 79, 272-279 (2014a)

12. V. Štejfa, M. Fulem, K. Ruzicka, C. Cervinka, J. Chem. Therm. 79, 280-289 (2014b) 
13. M. Torcal, M. Teruel, J. Garc1, J. Urieta, A. Mainar, J. Chem. Eng. Data 55, 5332-5339 (2010)

14. R. Yankova, V. Gandova, M. Dimov, K. Dobreva,V. Prodanova-Stefanova, A. Stoyanova, Oxi. Comm. 3, 293-306 (2019)

15. F. Incropera, D. Dewitt, T. Bergman, A. Lavine, John Wiley \&Sons (2006)

16. H. Topallar, Ü. Geçgel, Turk Journal Chemical 24, 247-253 (2000)

17. W. Yang, S. Sokhansanj, J. Tang, P. Winter, Biosys. Eng. 82, 2 169-176 (2002)

18. E. Georgiev and A. Stoyanova, A Guide for the Specialist in Aroma Industry, 1st ed. Plovdiv, Bulgaria: UFT Acad. Publ. House, (2006).

19. R. Belda, J. Herraez, O. Diez, Phys. and Chem. of Liq. 43, 1 91-101 (2005)

20. J. Khan, M. Farooqui, S.H. Quadri, Ras. J. Chem. 4, 4 944-946 (2011)

21. P. Florido, I. Andrade, M. Capellini, F. Carvalho, K. Aracava, C. Koshima, C. Rodrigues, C. Goncalves, J. Chem. Therm. 72, 152-160 (2014)

22. V. Gandova, S. Tasheva, K. Marinova, M. Dimov, K. Dobreva, V. ProdanovaStefanova, A. Stoyanova, Oxi. Comm. 43, 1 85-94 (2020)

23. S. Sepidar, Z. Abidin, R. Yunus, A. Muhammad, American J. of Appl. Sci. 6, 7 13901395 (2009)

24. O. Levenspiel, Chem. Reac. Eng., John Wily and Sons Inc. (2003)

25. Malijevsky, J. Novak, S. Labik, I. Malijevska, Phys. Chem. in brief, Institute of Chemical Technology (2005)

26. J. Tasheva, Oxi. Comm. 42, 4 443-451 (2019) 